\title{
Relationship of Angulation of Maxillary Impacted Canines with Maxillary Lateral Incisor Root Resorption
}

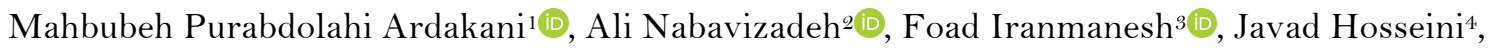 \\ Mahbubeh Nakhaei ${ }^{1}$
}

'Department of Oral and Maxillofacial Radiology, Qom Medical Sciences University, Qom, Iran.

${ }^{2}$ Department of Orthodontics, Dental School, Rafsanjan University of Medical Sciences, Rafsanjan, Iran

${ }^{3}$ Department of Endodontics, Dental School, Rafsanjan University of Medical Sciences, Rafsanjan, Iran.

${ }^{4}$ Department of Biostatistics, School of Public Health, Hamadan University of Medical Sciences, Hamadan, Iran.

Correspondence: Ali Nabavizadeh, Assistant Professor, Department of Orthodontics, Dental School, Rafsanjan University of Medical Sciences, Rafsanjan, Iran. E-mail: alnb1990@yahoo.com

Academic Editor: Ana Maria Gondim Valença

Received: 13 July 2020 / Review: 12 October 2020 / Accepted: 09 December 2020

How to cite: Purabdolahi Ardakani M, Nabavizadeh A, Iranmanesh F, Hosseini J, Nakhaei M. Relationship of angulation of maxillary impacted canines with maxillary lateral incisor root resorption. Pesqui Bras Odontopediatria Clín Integr. 2021 ; 21:e0164. https://doi.org/10.1590/pboci.2021.070

\begin{abstract}
Objective: To assess the relationship of $a$ and $\beta$ angles of maxillary impacted canines with maxillary lateral incisor root resorption. Material and Methods: For this, 40 patients (between 11 and 45 years) with impacted maxillary canines presenting to a private orthodontic clinic were evaluated. $20 \%$ of the cases were male and $80 \%$ were female. The $\mathrm{a}$ and $B$ angles were measured on panoramic radiographs to determine the angulation of impacted canine. CBCT scans had been taken by ProMax 3D CBCT system were used to examine lateral root reorption. The relationship between the size of $a$ and $B$ angles of impacted maxillary canines and root resorption in the adjacent maxillary lateral incisor was analyzed using SPSS version 22. Results: The mean size of $a$ and $B$ angles had no significant correlation with the presence/absence, location, or severity of root resorption in the adjacent lateral incisor or the buccolingual position of impacted canine. The $a$ and $B$ angles in impacted maxillary canines cannot be used to determine the incidence or severity of root resorption in the adjacent lateral incisor. Conclusion: No significant association between $a$ and $B$ angles and incidence or severity of root resorption in the adjacent lateral incisor was found.
\end{abstract}

Keywords: Tooth, Impacted; Root Resorption; Cone-Beam Computed Tomography. 


\section{Introduction}

Maxillary canine teeth have the highest rate of impaction after third molars [1]. Impaction of teeth seems to be multifactorial. Several factors have been proposed to play a role in impaction of maxillary canines. These factors can be divided into two groups of local and systemic factors; however, local factors play a more prominent role in this respect [1]. Local factors include improper location of tooth buds, presence of pathologies such as supernumeraries, odontoma, cysts or neoplastic lesions, long path of eruption, trauma, or delayed exfoliation of primary teeth [2-4]. The most important cause of impaction is the slow movement of impacted tooth towards the palatal surface. An erupting maxillary canine should move vertically towards the occlusal surface. However, impacted canines move towards the mesial and palatal directions [5,6].

Maxillary canine teeth determine the occlusion, shape, and function of dental arch [7]. Maxillary canine impaction has a prevalence rate of $0.8 \%$ to $2.8 \%$, and has a palatal orientation in $85 \%$ of the cases [ 8 ]. Maxillary canine impaction can cause several complications including periodontal problems, bone resorption in the adjacent areas, caries in the adjacent teeth, and root resorption of the adjacent teeth. Root resorption of the maxillary lateral incisor is the most common complication of maxillary canine impaction [9].

Patients with permanent maxillary canine impaction require an interdisciplinary treatment plan, which depends on accurate identification of the position of impacted canine [10,11]. Moreover, the presence and severity of root resorption in the adjacent lateral incisor and premolar should be determined. Evidence shows that both of the aforementioned parameters have a great impact on treatment planning by orthodontists and maxillofacial surgeons [8,12]. Also, time of treatment of impacted canine is highly important and is determined following precise assessment of tooth developmental stage [13]. Furthermore, the severity of root resorption of lateral incisor affects the prognosis of treatment and survival of the tooth [9].

Radiographic modalities are used to determine the exact position of impacted teeth. Periapical radiography can be used to assess the position of impacted canine and presence/absence of root resorption in the adjacent teeth [14]. However, two or more radiographs are required for more accurate assessment of impacted tooth in different spatial planes [15]. Occlusal radiograph can be used to determine the buccolingual position of impacted canines [15]. However, all these radiographic modalities have the possibility of superimposition of canine on the adjacent teeth due to their two-dimensional (2D) nature [16]. The diagnostic accuracy of panoramic radiography for impacted canines is still a matter of debate. Although panoramic radiographs provide little information about the buccolingual position of impacted teeth, it has been reported that the relationship of canine cusp tip and distal half of the root of lateral incisor may be a good indicator of palatal impaction of canine [17].

Evidence shows that cone-beam computed tomography (CBCT) is preferred to $2 \mathrm{D}$ imaging for determination of position of impacted canines [15]. However, it would be ideal to first request a panoramic radiograph to assess the possibility of other anomalies such as peg lateral incisors, missing premolars, or ectopic teeth, since they may be genetically related to canine impaction, and then a CBCT scan with a small field of view can be requested to better assess root resorption or position of impacted canine in more details [15]. By doing so, we can decrease the patient radiation dose, in comparison with requesting a full field CBCT in the first place [18].

Considering early detection of lateral root resorption by the impacted canines is a great help in a better treatment plan, and limited number of studies conducted on this topic, this study sought to assess the relationship of $a$ and $B$ angles of maxillary impacted canines with root resorption in the adjacent maxillary lateral incisor using panoramic radiography and CBCT. 


\section{Material and Methods}

Study Design and Sampling

This analytical, cross-sectional study evaluated 40 patients (with 40 impacted maxillary canines) presenting to a private orthodontic clinic in Rafsanjan city, who were selected using convenience sampling. Sample size was calculated to be 40 according to a study by Ezoddini et al. [19]. According to the objectives of this study (comparison of parameters in the two groups) and the minimum required sample size with $5 \%$ error and $80 \%$ power is 40 people in each group (accuracy of 0.08 ) [20].

$$
\left\{\begin{array}{ll}
\mathrm{n}_{1}=32 & \mathrm{n}_{2}=12 \\
\mu_{1}=46.63 & \mu_{2}=61.13 \\
\mathrm{~s}_{1}=18.58 & \mathrm{~s}_{2}=17.10
\end{array}\right\} \Longrightarrow \mathrm{n}=\frac{(1.96+0.84)^{2} \times 2 \times 329.743 \approx 40}{(14.5)^{2}}
$$

The mean age of patients was $18.2 \pm 6.55$ years (range 11 to 45 years). Of 40 patients, 8 (20\%) were males and $32(80 \%)$ were females. Of all cases of canine impaction, $14(35 \%)$ were in the right and $26(65 \%)$ were in the left side.

The inclusion criteria were age range of 11 to 45 years, having an impacted maxillary canine, presence of maxillary first molars, presence of mandibular teeth, having both panoramic radiograph and CBCT scan (taken as part of their orthodontic treatment and not for the purpose of this study), and visibility of C2 (cervical vertebra) on the panoramic radiograph. The exclusion criteria were rotation of impacted maxillary canine, rotation of maxillary first molar, vertical or horizontal dimension malocclusion, superimposition of the vertebral column over the mandibular ramus on panoramic radiograph, and patients with craniofacial syndromes or cleft lip and/or palate.

All CBCT scans had been taken by ProMax 3D CBCT system (Planmeca, Helsinki, Finland) with full maxilla field of view and the exposure settings of $66 \mathrm{kVp}, 9 \mathrm{~mA}$, and $16 \mathrm{~s}$ time. In romexis software 4.6.2 R, first on the sagittal plane, occlusal plane is set parallel to the ground then a curve was drawn on the reconstructed axial view, this curve passes exactly between the buccal and lingual cortical surfaces. Finally panoramic like and cross sectionals with a thickness of $2 \mathrm{~mm}$ were reconstructed, also check by scrolling all the coronal and axial cuts and the amount of lateral root resorption on each plane was recorded. All panoramic radiographs had been obtained by ProMax dental X-ray unit (Planmeca, Helsinki, Finland) with the exposure settings of 110 $\mathrm{kVp}$ and $10.65 \mathrm{~s}$ time.

Two landmarks were identified and used for assessment of canine angulation namely the $a$ and $\beta$ angles. The $\mathrm{a}$ angle is formed at the intersection of the occlusal line and longitudinal axis of canine tooth. The occlusal line is the line connecting the mesiobuccal cusp tips of the maxillary first molars. The a angle was measured for each impacted canine on the panoramic radiograph (Figure 1A). The $B$ angle is formed at the intersection of the cervical line and the longitudinal axis of impacted canine. The cervical line is the line connecting the most anterior and most inferior points of $\mathrm{C}_{2}$ (cervical vertebra). This angle was measured for each impacted canine on the panoramic radiograph (Figure 1B).

Presence/absence of root resorption in the adjacent lateral incisor was also evaluated on panoramic radiographs and recorded. Next, the CBCT scans of the maxilla in axial, sagittal and cross-sectional views were evaluated for presence/absence of root resorption in the lateral incisor. These measurements were performed by a maxillofacial radiologist. 
In case of presence of root resorption, its severity was classified in buccopalatal and mesiodistal dimensions using the following classification system [21]: Grade 0: Absence of resorption; Grade 1: Loss of natural contour of the root; Grade 2: Loss of $<50 \%$ of dentin; Grade 3: Loss of $\geq 50 \%$ of dentin without pulp involvement; and Grade 4: Pulp involvement.

The location of root resorption in the lateral incisors was categorized into three groups of apical third, middle third and cervical third [21]. Eventually, the relationship of the size of a and $\beta$ angles of the impacted maxillary canine on panoramic radiographs with root resorption in the adjacent lateral incisor was analyzed.
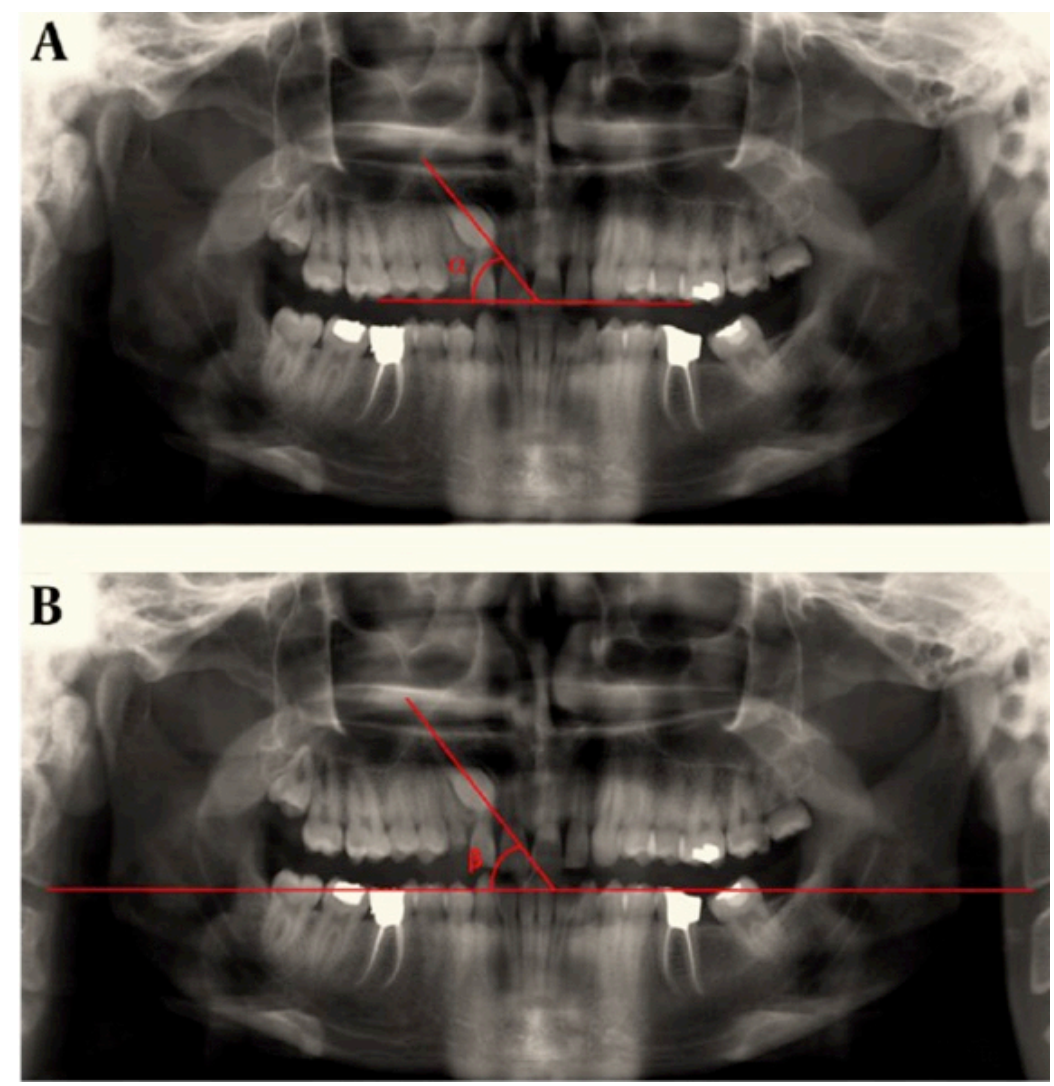

Figure 1. Measurement of $a(A)$ and $B(B)$ angles on a panoramic radiograph.

Data Analysis

Data were statistically analyzed using SPSS version 22 (SPSS Inc., IL, USA). The KolmogorovSmirnov test showed normal distribution of data regarding a and $\beta$ angles. Thus, parametric tests including the Chi-square test, t-test and Pearson's correlation test were applied for data analysis. If not significant, the Mann-Whitney and Spearman test and fisher's exact test were applied. The frequency and percentage values were reported for qualitative variables while the mean and standard deviation values were reported for quantitative variables. Level of significance was set at 0.05 .

Ethical Clearance

The study was approved by the ethics committee of our university (IR.RUMS.REC.1398.093).

\section{Results}


Based on panoramic radiographs, 11 cases (27.5\%) had root resorption and 29 (72.5\%) were sound. The location of resorption in one tooth $(2.5 \%)$ was in the cervical third, while it was in the middle third in 4 $(10 \%)$ and in the apical third of the lateral incisor root in $17(42 \%)$ teeth. CBCT revealed that 18 lateral incisors (45\%) did not have resorption, $9(22.5 \%)$ had grade 1 (Figure 2$), 5(12.5 \%)$ had grade 2 (Figure 3 ) and $8(20 \%)$ had grade 4 resorption (Figure 4). Grade 3 was not seen in any case.

Table 1 shows the mean size of $a$ and $B$ angles of impacted canine and their correlation with severity of root resorption in the adjacent lateral incisor. No significant correlation between the mean size of a angle and severity of root resorption $(\mathrm{p}=0.775)$. No significant correlation between the mean size of $\beta$ angle and severity of root resorption either $(\mathrm{p}=0.748)$.
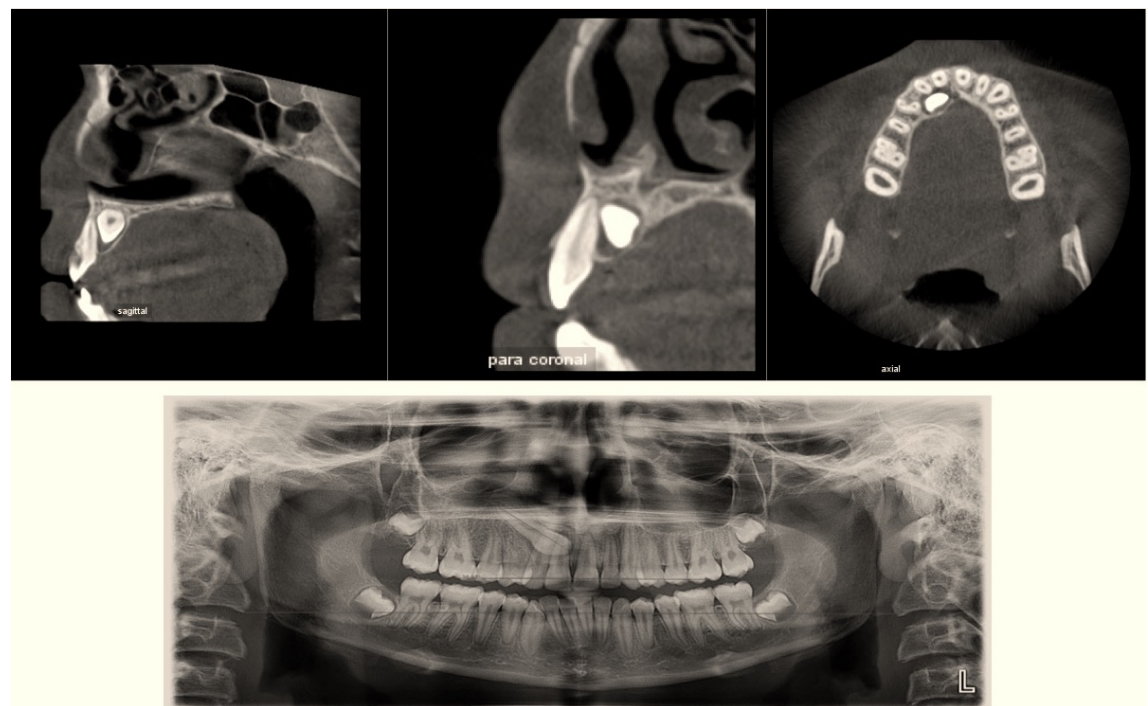

Figure 2. Grade 1 resorption in the apical third of the lateral incisor root.
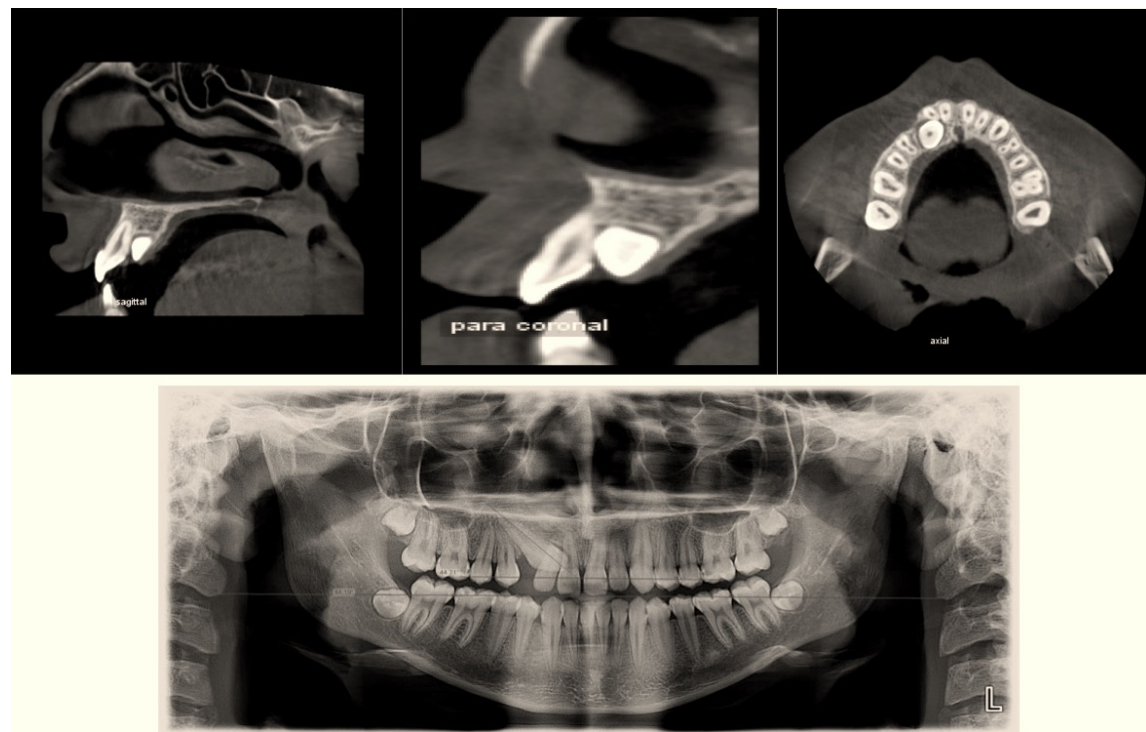

Figure 3. Grade 2 resorption in the middle third of the lateral incisor root. 

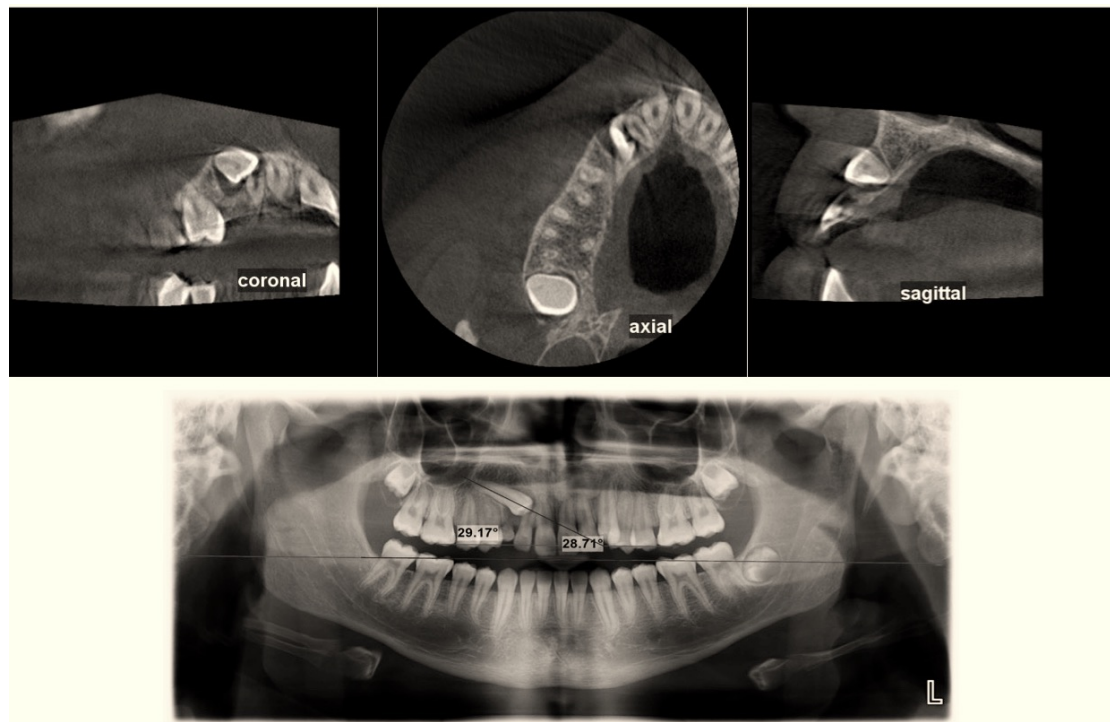

Figure 4. Grade 4 resorption in the apical third of the lateral incisor root.

Table 1. Comparison of the mean and standard deviation of $a$ and $\beta$ angles with respect to the intensity of root resorption in adjacent lateral teeth by one-way analysis of variance.

\begin{tabular}{|c|c|c|c|c|c|c|}
\hline \multicolumn{2}{|c|}{ Angle } & $\mathbf{N}$ & Mean & Std. Deviation & $\mathbf{F}$ & p-value \\
\hline \multirow[t]{5}{*}{ Alpha } & 0 & 18 & 56.07 & 18.25 & 0.371 & 0.775 \\
\hline & 1 & 9 & 51.03 & 12.99 & & \\
\hline & 2 & 5 & 51.23 & 14.05 & & \\
\hline & 4 & 8 & 49.32 & 20.10 & & \\
\hline & Total & 40 & 52.98 & 16.76 & & \\
\hline \multirow[t]{5}{*}{ Beta } & $\mathrm{O}$ & 18 & 55.87 & 18.45 & 0.409 & 0.748 \\
\hline & 1 & 9 & 49.83 & 13.17 & & \\
\hline & 2 & 5 & 51.52 & 12.99 & & \\
\hline & 4 & 8 & 49.07 & 20.43 & & \\
\hline & Total & 40 & 52.61 & 16.90 & & \\
\hline
\end{tabular}

According to t-test, the mean size of a angle had no significant correlation with gender $(\mathrm{p}=0.498$ in males and $\mathrm{p}=0.948$ in females). The mean size of $B$ angle had no significant correlation with gender either ( $\mathrm{p}=0.610$ in males and $\mathrm{p}=0.936$ in females).

Table 2 shows the mean size of $a$ and $B$ angles based on age range. The results showed no significant association between the mean size of $a$ and $\beta$ angles with age range $(p>0.05)$.

Table 2. Evaluation of age variables grouped with alpha and beta angles by t-test analysis.

\begin{tabular}{ccccccc}
\hline Angle & Age (Years) & N & Mean & Std. Deviation & T & p-value \\
\hline Alpha & $11-19$ & 25 & 50.60 & 16.78 & 0.997 & 0.250 \\
& $20-45$ & 15 & 56.96 & 16.52 & & 0.213 \\
Beta & $11-19$ & 25 & 50.01 & 16.93 & 0.883 & 0.50 \\
& $20-45$ & 15 & 56.95 & 16.50 & & \\
\hline
\end{tabular}

Table 3 presents the mean size of $\mathrm{a}$ and $\beta$ angles based on the location of root resorption. According to t-test, the mean size of $\alpha$ and $\beta$ angles had no significant correlation with the location of resorption $(p>0.05)$. Since resorption in the cervical third was only noted in one tooth, it was not included in statistical analysis. 
Table 3. Survey the relationship between mean angle $\alpha$ and $\beta$ angles the location of root resorption.

\begin{tabular}{ccccccc}
\hline & Angle & N & Mean & Std. Deviation & T & p-value \\
\hline \multirow{2}{*}{ Alpha } & Middle & 5 & 49.96 & 10.46 & 0/079 & 0.704 \\
& Apical & 17 & 50.60 & 16.85 & & 0.70 \\
& Middle & 5 & 49.38 & 11.28 & $0 / 090$ & \\
& Apical & 17 & 50.10 & 16.76 & & \\
\hline
\end{tabular}

Table 4 shows the mean size of $a$ and $B$ angles based on the presence/absence of root resorption in the adjacent lateral incisor on panoramic radiographs. According to t-test, the mean size of a and $\beta$ angles had no significant correlation with presence/absence of root resorption in the adjacent lateral incisor on panoramic radiographs $(\mathrm{p}=0.879$ for $\mathrm{a}$ and $\mathrm{p}=0.896$ for $\beta$ angle).

Table 4. Survey mean size of $\alpha$ and $\beta$ angles based on the presence/absence of root resorption in the adjacent lateral incisors on panoramic radiographs.

\begin{tabular}{ccccccc}
\hline Angle & Age (Years) & N & Mean & Std. Deviation & T & p-value \\
\hline Alpha & Absent & 29 & 53.24 & 15.78 & 0.157 & 0.879 \\
& Present & 11 & 52.30 & 19.96 & & 0.896 \\
\multirow{2}{*}{ Beta } & Absent & 29 & 52.83 & 16.22 & 0.132 & 0.42 \\
& Present & 11 & 52.03 & 19.42 & & \\
\hline
\end{tabular}

Of impacted canines, 7 (17.5\%) had been positioned buccally and 33 (82.5\%) had been positioned palatally. The exact test showed no significant correlation between the buccolingual position of impacted canine and presence/absence of root resorption in the adjacent lateral incisor on panoramic radiographs $(\mathrm{p}=0.075)$. The Pearson's correlation test revealed a strong correlation between the size of $a$ and $B$ angles $(\mathrm{r}=0.995, \mathrm{p}=0.000)$.

The exact test showed a significant correlation between the severity of root resorption in the adjacent lateral incisor and buccolingual position of impacted canine $(\mathrm{p}=0.040)$, and the severity of resorption was greater in lateral incisors adjacent to buccally positioned impacted canines. The quadrant of impacted canine had no significant correlation with root resorption or its severity in the adjacent lateral incisor on panoramic radiographs $(\mathrm{p}=1.00)$.

In order to assess the correlation of dependent variable i.e. severity of root resorption with independent variable i.e. size of a angle, the logistic regression test was applied, which revealed $\mathrm{R}^{2}=0.025$ and $\mathrm{B}=-0.026$, showing no significant correlation $(\mathrm{p}=0.342)$. The same result was obtained for $\mathrm{B}$ angle.

\section{Discussion}

This study assessed the relationship of $a$ and $\beta$ angles of maxillary impacted canines with maxillary lateral incisor root resorption on panoramic radiographs and CBCTscans. Of all cases of canine impaction, 14 $(35 \%)$ were in the right and $26(65 \%)$ were in the left side, which was in agreement with previous results [19,22,23], all conducted on the Iranian population. The age range of patients from 11 to 45 years is an important limitation of the study. Since the probability of root resorption increases with age, it is not possible to make an accurate assessment of presence and severity of the lateral incisors root resorption.

The prevalence of canine impaction is reportedly $1 \%$ to $3 \%[16,24]$ and it has a predilection for female gender [24-26]. In our study, 80\% of patients with canine impaction were females. This difference between males and females is due to the difference in craniofacial growthpatterns of males and females. However, it 
should be noted that our sample size was derived from patients of one private orthodontic clinic only, and females generally have a higher demand for orthodontic treatment. Multicenter studies with larger sample size are required on this topic.

In our study, most impacted canines $(82.5 \%)$ had a palatal position, which was in agreement with other studies [20,27]. However, the frequency of palatally positioned impacted canines in our study was higher than the value reported by Danaei and Shahidi [21] and lower than the value reported by Grover and Lorton [28]. Labial impaction is often due to space shortage in dental arch while palatal impaction may occur in presence of adequate space in dental arch [28]. Variability in prevalence and position of canine impaction in studies can be due to racial differences, sample collection criteria, and sample size [29].

Evidence shows that detection of root resorption by periapical radiography is not accurate [30,31]. Periapical radiography can detect root resorption in only $12 \%$ of the cases [31]. However, if combined with other imaging modalities such as panoramic radiography and lateral cephalometry, root resorption can be detected in 50\% of the cases [16,32]. CBCT 3D imaging has several applications in orthodontics and orthosurgery, and can significantly enhance the detection of root resorption [12]. However, voxel size can significantly affect the detection of primary or mild root resorption [33]. Considering the high accuracy of CBCT, the difference in detection of root resorption by panoramic radiography (detection of 11 cases) and CBCT (detection of 22 cases) in our study is justified. Also, Danaei and Shahidi [21] reported that teeth that showed no resorption on periapical and panoramic radiographs had clear resorption on CT scans. Moreover, conventional radiography underestimated the severity of resorption, which highlights the superior efficacy of $3 \mathrm{D}$ radiography for detection of root resorption.

According to Liu et al. [30] and Ericson and Kurol [15] root resorption in teeth adjacent to an impacted canine is common. Its prevalence rate was 55\% in our study. Also, most lateral incisors with root resorption were adjacent to palatally impacted canines in our study, which was different from the findings of Kim et al. [34]. This difference can be attributed to higher general prevalence of palatal canine impaction in our study.

The current study revealed that the severity of root resorption in the lateral incisor was higher when the impacted canine had a buccal position. No previous study has assessed this relationship to compare our results with. Further studies are required to confirm this relationship. Also, this study had a cross-sectional design. Considering the long and complex path of eruption of canine teeth [16], longitudinal studies are required for more accurate assessment of this relationship. Since buccal impaction is mainly due to space shortage, risk of contact of canine tooth crown with the root of lateral incisor would be higher. Another important factor to consider is that duration of canine impaction also affects the severity of root resorption in the adjacent lateral incisor. Also, size of dental follicle of impacted canine and the distance between the canine tooth crown and lateral incisor root can affect the occurrence of root resorption. Since these factors were not evaluated in this study, we cannot draw a definite conclusion regarding the correlation of severity of resorption with buccal position of impacted canines.

The current results found no significant association between the size of a angle and incidence or severity of root resorption in the adjacent lateral incisor, which was in agreement with the results of Guarnieri et al. [22]. They assessed the angles between the longitudinal axis of canine and the occlusal line, midline and the longitudinal axis of lateral incisor and confirmed the presence of a correlation between the angle formed by the longitudinal axis of canine and longitudinal axis of lateral incisor with the severity of root resorption of lateral incisor. No other significant correlations were noted. 
Another study measured the a angle to determine the position of impacted canines. They showed that the a angle had a significant correlation with the position of impacted canines, and when the impacted canines had a buccal position, the size of a angle was significantly higher compared with palatally positioned impacted canines [19]. According to their results and ours, the size of a angle may reveal the position of impacted canine. However, no correlation exists between the size of a angle and root resorption in the adjacent lateral incisor. Ezoddini et al. [19] found a significant correlation between the size of $\beta$ angle and position of impacted maxillary canines. They added that $B$ angle had a higher diagnostic value than the a angle in determining the tooth position. They showed a strong correlation between the $\mathrm{a}$ and $B$ angles, which was in agreement with our findings.

As mentioned earlier, the a angle is formed between the longitudinal axis of canine tooth and the occlusal line, and the occlusal line is influenced by vertical and horizontal malocclusions involving maxillary first molars or their absence. Thus, it is recommended to use $B$ angle instead of a angle for assessment of impacted maxillary canines. The results showed that by an increase in the size of $a$ and $\beta$ angles, the severity of root resorption in the lateral incisor decreased. However, this reduction was not significant. Therefore, the severity of root resorption of lateral incisors can be roughly estimated by measuring the a and $\beta$ angles. However, further studies are required on this topic. By an increase in the severity of resorption, the prognosis of lateral incisor would decrease. Thus, the severity of resorption should be evaluated to determine the prognosis of lateral incisor, and CBCT has superior efficacy for this purpose.

The current results showed that root resorption of lateral incisor had the highest frequency in the apical third and lowest frequency in the cervical third, which was in agreement with the results found in the literature [21,35]. However, Ericson and Kurol [32] reported that resorption had the highest frequency in the middle third of the root.

According to Alqerban et al. [33], medial inclination of impacted canine and its overlap with over half portion of lateral incisor is the most common cause of root resorption of lateral incisor. Since impacted canine is in contact with the middle and apical thirds of the adjacent lateral incisor root in $84 \%$ of the cases, higher rate of root resorption in the apical and middle thirds in our study is justified.

Future longitudinal studies are required to assess the correlation of buccolingual position of impacted canines and severity of root resorption in the adjacent lateral incisors. Also, the severity of root resorption in different stages of development of impacted canines should be evaluated. Furthermore, the correlation of dental follicle of impacted canines and the distance between the canine tooth crown and root of lateral incisor with the severity of resorption should be investigated in future studies to detect all possible factors affecting lateral incisor root resorption.

\section{Conclusion}

No significant association between $a$ and $B$ angles and incidence or severity of root resorption in the adjacent lateral incisor was found.

\section{Authors' Contributions}

\footnotetext{
MPA (iD) https://orcid.org/0000-0001-5961-7636

AN (iD) https://orcid.org/0000-0002-1043-2427

FI (iD) https://orcid.org/0000-0002-7220-776X

Conceptualization, Methodology, Formal Analysis, Investigation, Writing - Original Draft and Writing - Review and Editing.

Conceptualization, Methodology, Formal Analysis, Investigation, Writing - Original Draft and Writing - Review and Editing.

Conceptualization, Methodology, Formal Analysis, Investigation, Resources, Data Curation and Visualization.
} 


$\begin{array}{lll}\text { JH } & \text { Conceptualization, Methodology, Formal Analysis, Investigation, Resources, Data Curation and } \\ \text { VN } & \text { (Disualization. } \\ \text { Conceptualization, Methodology, Formal Analysis, Investigation, Resources, Data Curation and } \\ \text { Visualization. }\end{array}$

\section{Financial Support}

None.

\section{Conflict of Interest}

The authors declare no conflicts of interest.

\section{Data Availability}

The data used to support the findings of this study can be made available upon request to the corresponding author.

\section{References}

[1] Bishara SE, Kommer DD, McNeil MH, Montagano LN, Oesterle LJ, Youngquist HW. Management of impacted canines. Am J Orthod 1976; 69(4):371-87. https://doi.org/10.1016/0002-9416(76)90207-4

[2] McSherry P, Richardson A. Ectopic eruption of the maxillary canine quantified in three dimensions on cephalometric radiographs between the ages of 5 and 15 years. Eur J Orthod 1999; 21(1):41-8. https://doi.org/10.1093/ejo/21.1.41

[3] Mcsherry PF. The ectopic maxillary canine: a review. Br J Orthod 1998; 25(3):209-16. https://doi.org/10.1093/ortho/25.3.209

[4] Brin I, Solomon Y, Zilberman Y. Trauma as a possible etiologic factor in maxillary canine impaction. Am J Orthod Dentofacial Orthop 1993; 104(2):132-7. https://doi.org/10.1016/S0889-5406(05)81002-9

[5] Sacerdoti R, Baccetti T. Dentoskeletal features associated with unilateral or bilateral palatal displacement of maxillary canines. Angle Orthod 2004; 74(6):725-32.

[6] Ericson S, Kurol J. Resorption of incisors after ectopic eruption of maxillary canines: a CT study. Angle Orthod 2000; $70(6): 415-23$.

[7] Rossini G, Cavallini C, Cassetta M, Galluccio G, Barbato E. Localization of impacted maxillary canines using cone beam computed tomography. Review of the literature. Ann Stomatol 2012; 3(1):14-8.

[8] Haney E, Gansky SA, Lee JS, Johnson E, Maki K, Miller AJ, et al. Comparative analysis of traditional radiographs and cone-beam computed tomography volumetric images in the diagnosis and treatment planning of maxillary impacted canines. Am J Orthod Dentofacial Orthop 2010; 137(5):590-7. https://doi.org/10.1016/j.ajodo.2008.06.035

[9] Schmidt AD, Kokich VG. Periodontal response to early uncovering, autonomous eruption, and orthodontic alignment of palatally impacted maxillary canines. Am J Orthod Dentofacial Orthop 2007; 131(4):449-55. https://doi.org/10.1016/j.ajodo.2006.04.028

[10] Bedoya MM, Park JH. A review of the diagnosis and management of impacted maxillary canines. J Am Dent Assoc 2009; 140(12):1485-93. https://doi.org/10.14219/jada.archive.2009.0099

[11] Peck S, Peck L, Kataja M. The palatally displaced canine as a dental anomaly of genetic origin. Angle Orthod 1994; 64(4):250-6.

[12] Bjerklin K, Ericson S. How a computerized tomography examination changed the treatment plans of 80 children with retained and ectopically positioned maxillary canines. Angle Orthod 2006; 76(1):43-51.

[13] Litsas G, Acar A. A review of early displaced maxillary canines: etiology, diagnosis and interceptive treatment. Open Dent J 201 1; 5:39-47. https://doi.org/10.2174/1874210601105010039

[14] Lindauer SJ, Rubenstein LK, Hang WM, Andersen WC, Isaacson RJ. Canine impaction identified early with panoramic radiographs. J Am Dent Assoc 1992; 123(3):91-2. https://doi.org/10.14219/jada.archive.1992.006

[15] Ericson S, Kurol J. Resorption of maxillary lateral incisors caused by ectopic eruption of the canines: a clinical and radiographic analysis of predisposing factors. Am J Orthod Dentofacial Orthop 1988; 94(6):503-13. https://doi.org/10.1016/0889-5406(88)90008-x

[16] Mason C, Papadakou P, Roberts GJ. The radiographic localization of impacted maxillary canines: a comparison of methods. Eur J Orthod 2001; 23(1):25-34. https://doi.org/10.1093/ejo/23.1.25

[17] Jacobs SG. Localization of the unerupted maxillary canine: how to and when to. Am J Orthod Dentofacial Orthop 1999; 115(3):314-22. https://doi.org/10.1016/s0889-5406(99)70335-5.

[18] Scarfe WC, Farman AG. Cone-Beam Computed Tomography. In: White SC, Pharoah MJ, editors. Oral Radiology: Principles and Interpretation. $6^{\text {th }}$ ed. Philadelphia: Elsevier; 2009. p. 225-243.

[19] Ezoddini F, Yassaei S, Ghanea S. Diagnostic value of panoramic radiography in determining the position of impacted permanent maxillary canines. Avicenna J Dent Res 2016; 9(2):e34409.

[20] Machin D, Campbell MJ, Tan SB, Tan SH. Sample Size Tables for Clinical Studies. $3^{\text {rd }}$ ed. London: Wiley-Blackwell; 1997. 256p. 
[21] Danaei SM, Shahidi S. Radiographic and CT scan evaluation of root resorption of permanent incisors maxillary impacted carises. J Mashhad Dental School 2007; 3 1(Issue):125-32. https://doi.org/10.22038/JMDS.2007.1412

[22] Guarnieri R, Cavallini C, Vernucci R, Vichi M, Leonardi R, Barbato E. Impacted maxillary canines and root resorption of adjacent teeth: A retrospective observational study. Med Oral Patol Oral Cir Bucal 2016; 21(6):e743e750. https://doi.org/10.4317/medoral.21337.

[23] Sheikhi M, Nasrabadi M. Prediction of maxillary canine impaction with panoramic radiographs. Shahid Beheshti University Dental J 2008; 26(1):53-9.

[24] GoodarziPour D, Saeedi A, Bahrami N. Endodontics. Accuracy of panoramic, panoramic with palpation and tube shift technique to localize maxillary impacted cuspid. J Dent Med 2009; 22(3):99-105.

[25] Preda L, La Fianza A, Di Maggio EM, Dore R, Schifino MR, Campani R, et al. The use of spiral computed tomography in the localization of impacted maxillary canines. Dentomaxillofac Radiol 1997; 26(4):236-41. https://doi.org/10.1038/sj.dmfr.4600258

[26] Becker A, Smith P, Behar R. The incidence of anomalous maxillary lateral incisors in relation to palatally-displaced cuspids. Angle Orthod 1981; 51(1):24-9.

[27] Walker L, Enciso R, Mah J. Three-dimensional localization of maxillary canines with cone-beam computed tomography. Am J Orthod Dentofacial Orthop 2005; 128(4):418-23. https://doi.org/10.1016/j.ajodo.2004.04.033

[28] Grover PS, Lorton L. The incidence of unerupted permanent teeth and related clinical cases. Oral Surg Oral Med Oral Pathol 1985; 59(4):420-5. https://doi.org/10.1016/0030-4220(85)90070-2

[29] Bass TB. Observations on the misplaced upper canine tooth. Dent Pract Dent Rec 1967; 18(1):25-33.

[30] Liu DG, Zhang WL, Zhang ZY, Wu YT, Ma XC. Localization of impacted maxillary canines and observation of adjacent incisor resorption with cone-beam computed tomography. Oral Surg Oral Med Oral Pathol Oral Radiol Endod 2008; 105(1):91-8. https://doi.org/10.1016/j.tripleo.2007.01.030

[31] Ericson S, Kurol J. Radiographic examination of ectopically erupting maxillary canines. Am J Orthod Dentofacial Orthop 1987; 91(6):483-92. https://doi.org/10.1016/0889-5406(87)90005-9

[32] Ericson S, Kurol J. Incisor resorption caused by maxillary cuspids: a radiographic study. Angle Orthod 1987; $57(4): 332-46$.

[33] Alqerban A, Hedesiu M, Baciut M, Nackaerts O, Jacobs R, Fieuws S, et al. Pre-surgical treatment planning of maxillary canine impactions using panoramic vs cone beam CT imaging. Dentomaxillofac Radiol 2013; 42(19):20130157. https://doi.org/10.1259/dmfr.20130157

[34] Kim Y, Hyun HK, Jang KT. The position of maxillary canine impactions and the influenced factors to adjacent root resorption in the Korean population. Eur J Orthod 2012; 34(3):302-6. https://doi.org/10.1093/ejo/cjroo2

[35] Lai CS, Bornstein MM, Mock L, Heuberger BM, Dietrich T, Katsaros C. Impacted maxillary canines and root resorptions of neighbouring teeth: a radiographic analysis using cone-beam computed tomography. Eur J Orthod 2013; 35(4):529-38. https://doi.org/10.1093/ejo/cjs037 